\title{
Molecular-Weight Dependence of Quenching Rate of $\alpha$-Anthryl- polystyrene in Various Solvents as Studied by Laser-Pulse-Induced Delayed Fluorescence
}

\author{
Hideharu USHIKI, Kazuyuki HoRIE, Akio OKAMOTO, \\ and Itaru MITA \\ Institute of Space and Aeronautical Science, University of Tokyo, \\ Komaba,Meguro-ku, Tokyo 153, Japan.
}

(Received August 31, 1979)

\begin{abstract}
The effects of the degree of polymerization $(D P)$ and solvents on the rate of intraand inter-macromolecular quenching of triplet anthryl groups bound to polystyrene have been studied from the decay of delayed fluorescence in butanone at $30^{\circ} \mathrm{C}$ and cyclohexane at $40^{\circ} \mathrm{C}$ using a $10 \mathrm{~ns}$ nitrogen laser pulse. The rate constant $k_{\text {intra }}$ for intramacromolecular quenching of the triplet of anthrylpolystyrene by monomer unit in its own polystyryl chain was found to be independent of $D P$, with an average value of $1.2 \times 10^{3} \mathrm{~s}^{-1}$ in butanone and $3.2 \times 10^{2} \mathrm{~s}^{-1}$ in cyclohexane, while the intermacromolecular rate constant $k_{\text {inter }}$ for quenching by other polystyryl chains expressed in base $\mathrm{M}^{-1} \mathrm{~s}^{-1}$ is of the order of $10^{4}$ to $10^{6} \mathrm{M}^{-1} \mathrm{~s}^{-1}$ and approximately proportional to $D P^{-0.93}$ in butanone and to $D P^{-0.99}$ in cyclohexane for the range of $D P=44-2600$. The implications of these results are briefly discussed.
\end{abstract}

KEY WORDS Laser Pulse / Delayed Fluorescence / 9-Methylanthracene / $\alpha$ Anthrylpolystyrene / Intra- and Inter-macromolecular/Reaction / Quenching Rate Constant / Activation Control / Effective Equilibrium Concentration / Overlapping of Spherical Coils /

In a previous paper, ${ }_{1}^{1}$ we reported that the triplet of anthryl group, attached to the chain end of polystyrene, is quenched by a polystyryl chain, inter- and intra-molecularly, with rates much slower than those for diffusion-controlled reactions. The intramolecular quenching rate constant $k_{\text {intra }}$ was independent of the degree of polymerization $(D P)$ of polystyrene but the intermolecular quenching rate constant $k_{\text {inter }}$ decreased considerably with $D P$. The solvent used in our previous work was benzene, a good solvent for polystyrene. In this work, a similar study is undertaken in different solvents, to obtain, first, supporting data which will show that the quenching behaviors observed in previous work are not special in benzene, and second, to see in greater detail, the effect of solvents on the rate constants. The delayed fluorescence induced by $10 \mathrm{~ns}$ nitrogen laser pulse of anthracene-terminated polymer with $D P=25-2600$ is measured in butanone and cyclohexane, intermediate and poor solvents for PS respectively, and the results obtained are compared with those ob- tained previously in benzene.

\section{EXPERIMENTAL}

$\alpha$-Monoanthrylpolystyrene (PS-A) and $\alpha, \omega$-dianthrylpolystyrene (A-PS-A) are the same samples used in our previous work. ${ }^{1}$ Their molecular weight and molecular weight distributions as well as the contents of the anthryl groups are reproduced in Table I. The method of measurement of delayed fluorescence is also the same as that given in the previous paper. The time dependence of the delayed fluorescence emission was measured by using a $250 \mathrm{~kW}$ pulsed nitrogen laser (AVCO C950B) and a transient time converter (Riken Denshi TCE-1000S). Measurements were carried out on sample solutions deaerated by several freeze-pump thaw cycles of a high vacuum system (for anionic polymerization). A cut-off gate of $100 \mathrm{~ns}$ put between the photomultiplier and a preamplifier eliminated the influence of normal fluorescence just after irradiation on the 
Table I. Characterization of anthrylpolystyrene

\begin{tabular}{lcccc}
\hline & & & \multicolumn{1}{c}{$\begin{array}{c}\text { Anthryl group } \\
\text { at a chain end }\end{array}$} & Polymer type \\
\cline { 3 - 4 } & $M_{n}$ & $M_{w} / M_{n}$ & $\%$ & PS-A \\
25 & & 100 & PS-A \\
44 & $2.8 \times 10^{3}$ & 1.03 & 83 & PS-A \\
120 & $4.6 \times 10^{3}$ & 1.41 & 68 & PS-A \\
270 & $1.2 \times 10^{4}$ & 1.21 & 90 & A-PS-A \\
280 & $2.9 \times 10^{4}$ & 1.17 & 100 & PS-A \\
550 & $3.0 \times 10^{4}$ & 1.59 & 90 & A-PS-A \\
640 & $5.7 \times 10^{4}$ & 1.18 & 100 & A-PS-A \\
940 & $6.7 \times 10^{4}$ & 1.45 & 100 & A-PS-A \\
1300 & $9.8 \times 10^{4}$ & 1.38 & 100 & A-PS-A \\
2600 & $1.4 \times 10^{5}$ & 1.42 & 78 & \\
\hline
\end{tabular}

delayed fluorescence.

\section{RESULTS AND DISCUSSION}

Analysis of Delayed Fluorescence Decay Curve

As previously shown, the decay rate of the concentration of triplet anthryl group $\mathrm{T}^{*}$ is represented by eq 1 ,

$$
-\frac{\mathrm{d}\left[\mathrm{T}^{*}\right]}{\mathrm{d} t}=k_{1}\left[\mathrm{~T}^{*}\right]+k_{\mathrm{TT}}\left[\mathrm{T}^{*}\right]^{2}
$$

where $k_{\mathrm{TT}}$ is the rate constant for the triplet-triplet interaction ( $\mathrm{T}-\mathrm{T}$ annihilation) and the apparent first order rate constant $k_{1}$ is given by eq 2 ,

$$
k_{1}=\left(k_{\mathrm{d}}^{\mathrm{T}}+k_{\text {intra }}\right)+\left(k_{\mathrm{cq}}+k_{\text {inter }} D P\right)\left[\mathrm{S}_{0}\right]
$$

in which $k_{\mathrm{d}}, k_{\mathrm{cq}}, k_{\text {intra }}$, and $k_{\text {inter }}$ are rate constants for radiationless transition, concentration quenching, intramolecular quenching by own polymer chain itself, intermolecular quenching by other polymer chains and $\left[\mathrm{S}_{0}\right]$ is the concentration of the ground state anthryl group. The intensity of delayed fluorescence at later stage of the decay curve is expressed by eq 3 ,

$$
\begin{aligned}
I_{\mathrm{DF}} & =z k_{\mathrm{TT}}\left[\mathrm{T}^{*}\right]^{2} \\
& =z k_{\mathrm{TT}}\left(\frac{k_{1}\left[\mathrm{~T}^{*}\right]_{0}}{k_{1}+k_{\mathrm{TT}}\left[\mathrm{T}^{*}\right]_{0}}\right)^{2} \exp \left(-2 k_{1} t\right)
\end{aligned}
$$

where $z$ is the emission efficiency of triplet-triplet interaction. The value of $k_{1}$ can easily can be obtained from the slope of the linear line of semilogarithmic plots. By using two values of $k_{1}$ obtained at two different concentrations of anthryl group $\left[\mathrm{S}_{0}\right]$ or in other words, at two different polymer concentrations, $\left(k_{\mathrm{d}}{ }^{\mathrm{T}}+k_{\text {intra }}\right)$ and $\left(k_{\mathrm{cq}}+k_{\text {inter }} D P\right)$ could be calculated. As for the values of $k_{\mathrm{d}}{ }^{\mathrm{T}}$ and $k_{\mathrm{cq}}$, those for methylanthracene (the model reaction), obtained separately, were used. These values were $k_{\mathrm{d}}{ }^{\mathrm{T}}=6.6 \times 10^{2} \mathrm{~s}^{-1}$ and $k_{\mathrm{cq}}=3.5 \times 10^{5} \mathrm{M}^{-1} \mathrm{~s}^{-1}$ in butanone and $k_{\mathrm{d}}{ }^{\mathrm{T}}=8.3 \times 10^{2} \mathrm{~s}^{-1}$ and $k_{\mathrm{cq}}=$ $3.1 \times 10^{6} \mathrm{M}^{-1} \mathrm{~s}^{-1}$ in cyclohexane respectively. The $k_{\text {intra }}$ and $k_{\text {inter }}$ are obtained by subtraction.

\section{Quenching of Triplet Methylanthracene by Poly- styrene}

The quenching reaction of the anthryl group by the polystyryl chain occurs for a small molecule (methylanthracene, abbreviated as MA)-polymer (polystyryl chain) system as well as for the PS-A system. ${ }^{1}$ In keeping methylanthracene concentration constant $\left(2.5 \times 10^{-4} \mathrm{M}\right), k_{1}$ for methylanthracene was measured in the presence of PS $(D P \fallingdotseq 22)$ at various concentrations in butanone and cyclohexane. The results are shown in Figure 1. For this system, $k_{1}$ is represented by eq 4 ,

$$
k_{1}=\left(k_{\mathrm{d}}{ }^{\mathrm{T}}+k_{\mathrm{cq}}\left[\mathrm{S}_{0}\right]\right)+k_{\text {inter }}^{0}[\mathrm{St}]
$$

where $k_{\text {inter }}^{0}$ is the rate constant for model reaction, i.e. the deactivation of triplet methylanthracene by a monomer unit of the polystyryl chain. Figure 1 shows that $k_{1}$ is really a linear function of the polystyrene concentration in the case of butanone as it is for benzene as well. The value of $k_{\text {inter }}^{0}$ thus obtained is $3.2 \times 10^{2} \mathrm{M}^{-1} \mathrm{~s}^{-1}$ in butanone at $30^{\circ} \mathrm{C}$. But, in cyclohexane, eq 4 failed to hold. The anomalous dependence of the quenching rate on the 


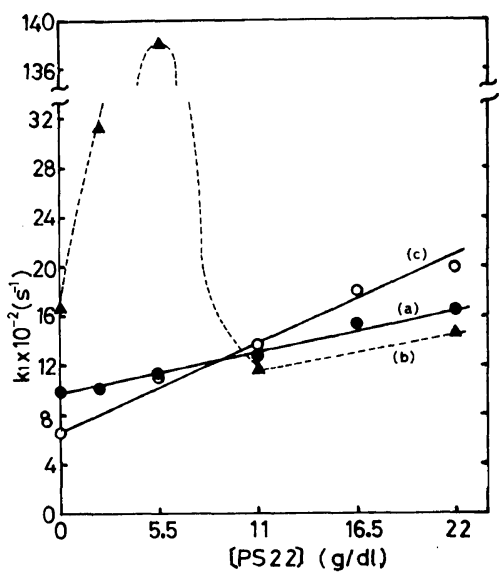

Figure 1. The values of $k_{1}$ at different concentrations of PS22 in various solvents: (a), in butanone at $30^{\circ} \mathrm{C}$; (b), in cyclohexane at $40^{\circ} \mathrm{C} ; \bigcirc(\mathrm{c})$, in benzene at $30^{\circ} \mathrm{C}$; concentration of methylanthracene, $2.5 \times 10^{-4} \mathrm{M}$.

polystyrene concentration may be attributed to the very low solubility of methylanthracene in cyclohexane.* The low solubility may induce a selective adsorption of methylanthracene on polystyrene which affects the course of reaction in cyclohexane. On the other hand, eq 2 holds for the PS-A and A-PS-A systems even in cyclohexane. This is understandable because the terminal anthryl group may be solubilized by its polystyrene tail.

With butanone, it is possible to estimate the collision frequency between methylanthracene and a monomer unit of polystyrene for the MA-PS22 system by using the rate constant for the diffusioncontrolled intermolecular reaction between two particles, $k_{\mathrm{D}}$, since a monomer unit in the PS22 is supposed to be randomly distributed in a concentrated polymer solution. The ratio $\beta \equiv k_{\text {inter }}^{0} / k_{\mathrm{D}}$ represents the quenching efficiency of the collision of a monomer unit of polystyrene with methylanthracene. With the value of $k_{\text {inter }}^{0}$ already given and $k_{\mathrm{D}}=8 R T / 2 \times 3000 \eta_{0}$ where $\eta_{0}$ is the viscosity of solvent, $\beta$ is calculated as $3.8 \times 10^{-8}$ in butanone at $30^{\circ} \mathrm{C}$, showing that quenching takes place only once during $2.6 \times 10^{7}$ collisions.

* Furthermore, the $k_{\mathrm{cq}}$ of methylanthracene in the absence of polystyrene in cyclohexane is larger than that in either benzene or butanone, and $k_{1}=k_{\mathrm{d}}{ }^{\mathrm{T}}+k_{\mathrm{cq}}\left[\mathrm{S}_{0}\right]$ failed to hold at high concentration of mëthylanthracene $\left(\sim 10^{-3} \mathrm{M}\right)$ in cyclohexane.
Intramacromolecular Quenching Rate between Chain End Groups and Monomer Units in the Same Polymer Chain

The intramolecular queching rate constants $k_{\text {intra }}$ obtained by the method described above are given in Table II. They are also plotted against $D P$ in Figure 2 . Though they scatter rather widely they are almost independent of $D P$, as in the benzene solution. The average values of $k_{\text {intra }}$ are $1.2 \times 10^{3} \mathrm{~s}^{-1}$ in butanone and $3.2 \times 10^{2} \mathrm{~s}^{-1}$ in cyclohexane; these values may be compared with that previously reported for benzene, $1.0 \times 10^{3} \mathrm{~s}^{-1}$.

The intramolecular quenching rate constant $k_{\text {intra }}$ may be regarded as the sum of the rate constants for quenching by monomer units located at various positions from the triplet anthryl group bound to the chain end, i.e.,

$$
k_{\text {intra }}=\sum_{n=1}^{\infty} k_{\text {intra }}^{(n)}
$$

where $k_{\text {intra }}^{(n)}$ is the first-order rate constant for a reaction between the triplet anthryl group and the $n$ th monomer unit from the chain end. The values of $k_{\text {intra }}^{(n)}$ must be governed by the existence probability at equilibrium of cyclic conformation with the anthryl group (at the chain end) and the $n$-th monomer unit in the same small reaction sphere. Let the effective equilibrium concentration of the $n$-th monomer unit in the neighborhood of the chain end be $C_{\text {eff }}^{(n)}$ and the intrinsic second order rate constant for a model reaction of two small molecules be $k_{\text {inter }}^{0}$, $k_{\text {intra }}^{(n)}$ is the given by eq 6 .

$$
k_{\text {intra }}^{(n)}=k_{\text {inter }}^{0} C_{\text {eff }}^{(n)}
$$

Thus,

$$
k_{\text {intra }}=k_{\text {inter }}^{0} \sum_{n=1}^{\infty} C_{\text {eff }}^{(n)}=k_{\text {inter }}^{0} C_{\text {eff }}
$$

where $C_{\text {eff }}=\sum_{n=1}^{\infty} C_{\text {eff }}^{(n)}$ is the effective overall concentration of the monomeric units of the chain around the reactive chain end. If the distance from the chain end to the $n$-th monomeric unit is regarded as an end-to-end distance of a simple $n$-mer which obeys gaussian distribution and the reaction sphere is very small, then, as reported by Goodman and Morawetz, ${ }^{2} C_{\text {eff }}^{(n)}$ is expressed by eq 8 ,

$$
C_{\text {eff }}^{(n)}=\left(1000 / N_{0}\right)\left(3 / 2 \pi\left\langle h^{2}(n)\right\rangle\right)^{3 / 2}
$$


H. UshiKI, K. Horie, A. OKamoto, and I. Mita

Table II. The $k_{1}$ value of different concentrations of MA, PS-A and A-PS-A

in butanone at $30^{\circ} \mathrm{C}$ and cyclohexane at $40^{\circ} \mathrm{C}$

\begin{tabular}{|c|c|c|c|c|}
\hline Polymer & $\frac{\text { Concentration }}{\times 10^{-4} \mathrm{M}}$ & $\frac{k_{1}}{\times 10^{-3} \mathrm{~s}^{-1}}$ & $\frac{k_{\text {intra }}}{\times 10^{-2} \mathrm{~s}^{-1}}$ & $\frac{k_{\text {inter }}}{\times 10^{-4} \mathrm{~s}^{-1} \mathrm{M}^{-1}}$ \\
\hline $\begin{array}{l}\text { Butanone } \\
\text { MA }\end{array}$ & $\begin{array}{l}2.5 \\
0.50\end{array}$ & $\begin{array}{l}0.75 \\
0.68\end{array}$ & & \\
\hline PS25A & $\begin{array}{l}2.5 \\
0.50\end{array}$ & $\begin{array}{l}3.2 \\
1.6\end{array}$ & 6.3 & 30 \\
\hline PS44A & $\begin{array}{l}2.3 \\
0.46\end{array}$ & $\begin{array}{l}9.5 \\
2.8\end{array}$ & 5.1 & 83 \\
\hline PS120A & $\begin{array}{l}2.9 \\
0.59\end{array}$ & $\begin{array}{l}8.5 \\
2.9\end{array}$ & 8.7 & 20 \\
\hline PS270A & $\begin{array}{l}2.0 \\
0.39\end{array}$ & $\begin{array}{l}8.0 \\
2.7\end{array}$ & 6.9 & 13 \\
\hline APS280A & $\begin{array}{l}1.3 \\
0.63\end{array}$ & $\begin{array}{l}6.8 \\
4.5\end{array}$ & 16 & 13 \\
\hline PS550A & $\begin{array}{l}1.8 \\
0.37\end{array}$ & $\begin{array}{l}7.9 \\
2.4\end{array}$ & 4.2 & 6.8 \\
\hline APS640A & $\begin{array}{l}1.2 \\
0.31\end{array}$ & $\begin{array}{l}7.0 \\
2.5\end{array}$ & 4.2 & 7.5 \\
\hline APS940A & $\begin{array}{l}1.2 \\
0.31\end{array}$ & $\begin{array}{l}8.4 \\
4.5\end{array}$ & 26 & 4.4 \\
\hline APS1300A & $\begin{array}{l}1.2 \\
0.29\end{array}$ & $\begin{array}{l}7.1 \\
4.5\end{array}$ & 30 & 2.3 \\
\hline APS $2600 \mathrm{~A}$ & $\begin{array}{l}1.1 \\
0.27\end{array}$ & $\begin{array}{l}6.3 \\
2.8\end{array}$ & 10 & 1.7 \\
\hline $\begin{array}{l}\text { Cyclohexane } \\
\text { MA }\end{array}$ & $\begin{array}{l}2.5 \\
0.50\end{array}$ & $\begin{array}{l}1.6 \\
0.99\end{array}$ & & \\
\hline PS25A & $\begin{array}{l}5.0 \\
1.0\end{array}$ & $\begin{array}{l}3.2 \\
1.3\end{array}$ & - & 19 \\
\hline PS44A & $\begin{array}{l}2.3 \\
0.46\end{array}$ & $\begin{array}{l}7.4 \\
2.0\end{array}$ & - & 66 \\
\hline PS120A & $\begin{array}{l}2.9 \\
0.59\end{array}$ & $\begin{array}{l}5.7 \\
1.7\end{array}$ & - & 14 \\
\hline PS270A & $\begin{array}{l}2.0 \\
0.39\end{array}$ & $\begin{array}{l}5.4 \\
2.0\end{array}$ & 1.5 & 8.2 \\
\hline PS550A & $\begin{array}{l}0.66 \\
0.37\end{array}$ & $\begin{array}{l}2.7 \\
2.2\end{array}$ & 6.0 & 3.1 \\
\hline APS2600A & $\begin{array}{l}1.4 \\
0.27\end{array}$ & $\begin{array}{l}5.0 \\
1.9\end{array}$ & 2.0 & 1.1 \\
\hline
\end{tabular}

where $N_{0}$ is Avogadro's number and $\left\langle h^{2}(n)\right\rangle$ is the mean-square end-to-end distance of $n$-mer. In $\Theta$ solvent, $\left\langle h^{2}(n)\right\rangle$ is proportional to $n$ so that $C_{\text {eff }}^{(n)}$ is proportional to $n^{-3 / 2}$ while in good solvents $C_{\text {eff }}^{(n)}$ is approximately proportional to $n^{-1.8 \sim-2.0}$. In any case, $C_{\text {eff }}^{(n)}$ decreases rapidly with $n$ and their sum over the initial 20-25 terms accounts for a substantial part of $C_{\text {eff }}$ which is the sum going to infinity; for example,

$$
\left(\sum_{n=1}^{25} n^{-2}\right) /\left(\sum_{n=1}^{\infty} n^{-2}\right)=1.606 / 1.645=0.98
$$

and

$$
\left(\sum_{n=1}^{25} n^{-1.5}\right) /\left(\sum_{n=1}^{\infty} n^{-1.5}\right)=2.17 / 2.61=0.85
$$

Polymer J., Vol. 12, No. 1, 1980 


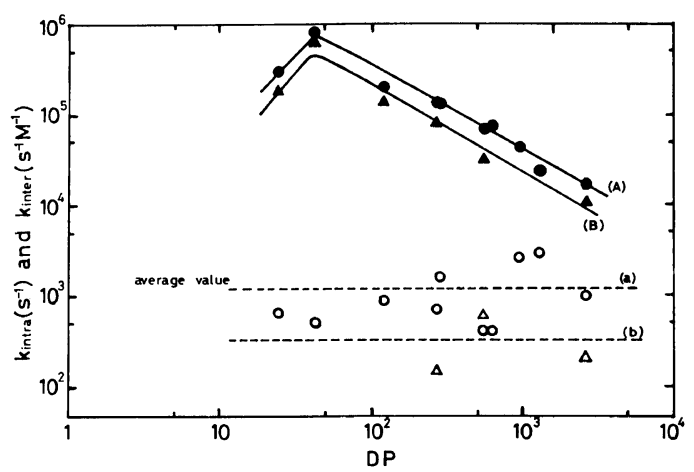

Figure 2. The intra- and inter-macromolecular quenching rate constants of triplet anthryl group with anthrylpolystyrene by polystyryl chains, $k_{\text {intra }}$ and $k_{\text {inter }}$ against degree of polymerization $D P: \bigcirc(\mathrm{A}), k_{\text {inter }}$ in butanone at $30^{\circ} \mathrm{C} ; \Delta(\mathrm{B}), k_{\text {inter }}$ in cyclohexane at $40^{\circ} \mathrm{C} ; \bigcirc(\mathrm{a}), k_{\text {intra }}$ in butanone at $30^{\circ} \mathrm{C} ; \triangle(\mathrm{b}), k_{\text {intra }}$ in cyclohexane at $40^{\circ} \mathrm{C}$.

Consequently, it is obvious that remote units from the chain end contribute little to $k_{\text {intra }}$ and that the latter must be almost constant for range $n$ larger than $20-25$. Of course, in a small $n$ region, the hypothesis of the gaussian distribution of end-to-end distance does not hold. But the argument that the remote units do not contribute to $k_{\text {intra }}$ should be always valid and the observed fact that $k_{\text {intra }}$ is independent of $D P$ over 20 (the lowest $D P$ studied) is quite consistent with this argument.

In contrast to the absolute value of $k_{\text {intra }}$, its ratio to $k_{\text {inter }}^{0}$, i.e., $C_{\text {eff }}$ may not be affected much by the type of reaction and the reactive species and may be governed mainly by the solution properties of the polymer chain used provided that the radius of the reaction sphere does not differ appreciably. In poor solvents, where the local concentration of monomeric unit is higher (or $\left\langle h^{2}(n)\right\rangle$ is smaller) than in good solvents, $C_{\text {eff }}$ must be larger. As found out experimentally, this is actually the case. $C_{\text {eff }}$ is $3.7 \mathrm{M}$ $\left(1.2 \times 10^{3} / 3.2 \times 10^{2}\right)$ in butanone (poor solvent) as compared to $1.7 \mathrm{M}\left(1.0 \times 10^{3} / 6.2 \times 10^{2}\right)$ in benzene (good solvent). These values of $C_{\text {eff }}$ and their tendency to decrease in good solvents agree well with those found by Goodman and Morawetz ${ }^{2}$ who obtained $C_{\text {eff }}$ values of $2.8 \mathrm{M}$ in water and $4.5 \mathrm{M}$ in a $40 \%$ methanol aqueous solution for the polyacrylamide chain; the reaction they studied was the pyridine catalysed hydrolysis of $p$-nitrophenyl isobutylate analog (pyridine and $p$-nitrophenyl groups that are incorporated by copolymerization into polyacrylamide chain).

On the other hand, Sisido et $a .^{3}$ studied the rates of the same intramolecular hydrolysis, but with the two functional groups attached to the both chain ends of oligosarcosine or oligoethyleneoxide molecules. The values of $C_{\text {eff }}^{(n)}$ they obtained are of the order of $10^{-2} \mathrm{M}$ and decreased with increasing $n$ (the lowest number of the main chain atoms between the two functional groups studied is about 20), and the summation over $n$ for each oligomer amounts only to the order of $10^{-1} \mathrm{M}$ which is by about $10^{-1}$ as low as our values and those found by Goodman and Morawetz. ${ }^{2}$ The reason for this disagreement is not yet clear but one possible explanation is that the values of $C_{\text {eff }}$ found by us and those found by Goodman and Morawetz contain a large contribution of rate constants for reactions having very small cyclic conformations (less than 20 chain atoms) not yet studied and can not be counted in the summation of Sisido's experiment.

Knowing the collision efficiency $\beta$ given in the preceding section, the intramacromolecular collision rate constant of a terminal anthryl group with the monomer units on the chain, $k_{\text {intra }}^{\mathrm{c}}$, can be calculated by using the relation $k_{\text {intra }}^{\mathrm{c}}=k_{\text {intra }} / \beta$. The value of $k_{\text {intra }}^{\mathrm{c}}$ thus obtained is $3.1 \times 10^{10} \mathrm{~s}^{-1}$ in butanone (and $1.0 \times 10^{10} \mathrm{~s}^{-1}$ in benzene). ${ }^{1}$ These values, which are always the sum of the collision frequencies for each chain length, have a value of expected order of magnitude because the intramacromolecular collison frequencies are known to be of the order of $10^{9}$ to $10^{10} \mathrm{~s}^{-1}$ and decrease roughly in proportion with $n^{-3 / 2} \cdot{ }^{4-5}$

\section{Intermacromolecular Quenching Rates between Chain} End Group and Monomer Units in Other Polymer Chains

The intermacromolecular quenching rate constants $k_{\text {inter }}$ are also given in Table II and their dependence on $D P$ is shown in Figure 2. These curves have a peak at around $D P=30-50$ and then decrease linearly with increasing $D P$ on a $\log$-log scale. The behavior of these curves is completely identical to that in benzene reported already. ${ }^{1}$ The exponent $m$ in the relation $k_{\text {inter }} \propto D P^{-m}$ determined by the least-squares method is 0.93 in butanone at $30^{\circ} \mathrm{C}$ and 0.99 in cyclohexane at $40^{\circ} \mathrm{C},(m=0.79$ in benzene at $\left.30^{\circ} \mathrm{C}\right){ }^{1}$

In our previous work, ${ }^{1}$ the interesting $D P$ dependence of $k_{\text {inter }}$ for these activation-controlled 
polymer-polymer reactions has been briefly discussed. In the case of a polymer-small molecule reaction, the rate of the intermolecular quenching reaction is expressed by eq 9 ,

$$
-\frac{\mathrm{d}\left[\mathrm{T}^{*}\right]}{\mathrm{d} t}=\frac{V_{\mathrm{p}}}{V} k_{\text {inter }}^{0}\left[\mathrm{~T}^{*}\right]_{\mathrm{in}}[\mathrm{St}]_{\mathrm{in}}=k_{\text {inter }}^{0}\left[\mathrm{~T}^{*}\right][\mathrm{St}]
$$

where $V$ is the total volume, $V_{\mathrm{p}}$ the total volume occupied by the polymer coils and $\mathrm{T}^{*}$ the triplet state molecule, and [ $]_{\text {in }}$ is the concentration inside the polymer coil which differs from the average concentration [ ] in a usual sense in the case of a styrene monomer unit; however both have the same value for $\mathrm{T}^{*}$ because $\mathrm{T}^{*}$ moves freely inside and outside the polymer sphere. Consequently, the rate constants are the same for the small molecule-small molecule model reaction $\left(k_{\text {inter }}^{0}\right)$ and for the polymer-small molecule reaction. ${ }^{6}$ On the other hand, in the case of a polymer-polymer reaction, the movement of the triplet anthryl group bound to polymer chain may be much slower inside the coil of another polymer molecuule than that outside the coil because the triplet carries a long polymer tail. As a result, the time averaged concentration of $\mathrm{T}^{*}$ inside the polymer coil $\left[\mathrm{T}^{*}\right]_{\text {in }}$ increases and the apparent rate constant $k_{\text {inter }}=k_{\text {inter }}^{0}\left[\mathrm{~T}^{*}\right]_{\text {in }} /\left[\mathrm{T}^{*}\right]$ increases, as is observed in this and other work. However, when the $D P$ of polymer becomes sufficiently high, another factor making $k_{\text {inter }}$ lower, has to be taken into consideration.

Based on Olaj's theory, ${ }^{7}$ it has been assumed that only the thin outer layers of the two spherical coils overlap in dilute solution, and the reaction occurs only in this small overlapped region. Thus the rate of intermacromolecular quenching reaction is expressed by eq 10 ,

$$
\begin{aligned}
-\frac{\mathrm{d}\left[\mathrm{PS}-\mathrm{A}^{*}\right]}{\mathrm{d} t} & =\frac{V_{\text {overlap }}}{V} k_{\text {inter }}^{0}\left[\mathrm{PS}-\mathrm{A}^{*}\right]_{\mathrm{in}}[\mathrm{St}]_{\mathrm{in}} \\
& =\left(\frac{3 d^{2}}{8 R^{2}}\right)\left(\frac{V_{\mathrm{p}}}{V}\right) k_{\text {inter }}^{0}\left[\mathrm{PS}-\mathrm{A}^{*}\right]_{\mathrm{in}}[\mathrm{St}]_{\mathrm{in}} \\
& =\left(\frac{3 d^{2}}{8 R^{2}}\right) k_{\text {inter }}^{0}\left[\mathrm{PS}-\mathrm{A}^{*}\right]_{\mathrm{in}}[\mathrm{St}] \\
& =k_{\text {inter }}\left[\mathrm{PS}-\mathrm{A}^{*}\right][\mathrm{St}]
\end{aligned}
$$

where $R$ is the radius of the coil and $d$, the thickness of the lens-liked overlapped region. Consequently, the apparent rate constant $k_{\text {inter }}$ should be affected by the parameters $d$ and $R$. In an earlier work, ${ }^{1}$ the overlapping thickness, $d$, is assumed to be constant irrespective of $D P$. The apparent rate constant $k_{\text {inter }}$ should thus be proportional to $D P^{-1}$, because $R$ is roughly proportional to $D P^{1 / 2}$. The present results also agree as a first approximation with the expectation given above.

However, when the effect of different solvents on $k_{\text {inter }}$ is examined in more detailed, there is a small but definite tendency that is in conflict with the explanation given above. It is well known that in the relation $R \propto D P^{\mathrm{b}}$ (where $R$ is simply regarded as a root mean square of radius of gyration), $b$ is equal to $1 / 2$ in $\Theta$ solvent but it is larger in better solvents. More quantitatively, $b=(1+a) / 3$ where $a$ is the exponent in Mark-Howink-Sakurada's relation $[\eta]=K M^{\text {a }}$; for example, $a=0.74,0.60$, and 0.50 for polystyrene in benzene, ${ }^{8}$ in butanone ${ }^{9}$ and in cyclohexane ${ }^{10}$ respectively. Consequently, if the interpenetration thickness $d$ were strictly constant and independent of $D P$, the value of the exponent $m$ in the relation $k_{\text {inter }} \propto D P^{-m}$ would be larger in better solvent. But this is not the case. On the contrary, $m$ is larger in a poor solvent as was mentioned earlier. Hence, the overlapping thickness should not be considered as constant in a strict meaning and it increases with $D P$, especially in the case of good solvent. This result seems reasonable because the segment density per unit volume inside the polymer coil with a same $D P$ is lower in a good solvent than in a poor solvent and it decreases with $D P$ more rapidly in the former than in the latter. If the simple theory mentioned already, that $k_{\text {inter }}$ is proportional to $d^{2} / R^{2}$, is valid, by using the values of $m$ obtained experimentally and those of $a$, the dependence of $d$ on $D P\left(d \propto D P^{x}\right)$ can thus be calculated accofding to the relation $x=[(1+a) / 3]-[m / 2]$. The $x$ thus obtained is 0.19 in benzene, 0.07 in butanone and practically zero in cyclohexane.

\section{CONCLUSION}

The quenching rates of triplet anthryl group attached to the chain end of monodisperse polystyrene by polystyryl chains have been measured in butanone and in cyclohexane using the decay of $\mathbf{P}$ type delayed fluorescence as a monitoring means. In order to understand the effect of solvents on the quenching rate constants, the kinetic parameters of anthrylpolystyrene obtained in various solvents are summarized in Table III. The present work con- 
Study on Quenching Rate of Anthrylpolystyrene

Table III. The kinetic parameters of anthrylpolystyrene in various solvents

\begin{tabular}{lccccc}
\hline Solvent & $\mathrm{Temp} /{ }^{\circ} \mathrm{C}$ & $k_{\text {intra }} / \times 10^{-3} \mathrm{~s}^{-1}$ & $k_{\text {intra }}^{\mathrm{c}} / \times 10^{-10} \mathrm{~s}^{-1}$ & $C_{\text {eff }} / \mathbf{M}$ & $m^{\mathrm{a}}$ \\
\hline Benzene & 30 & 1.0 & 1.0 & 3.7 & 0.79 \\
Butanone & 30 & 1.2 & 3.1 & - & 0.93 \\
Cyclohexane & 40 & 0.32 & - & - & 0.99 \\
\hline
\end{tabular}

a $m$, the exponent $m$ in the relation of $k_{\text {inter }} \propto D P^{-m}$.

firmed the results obtained previously in benzene solution that the intramacromolecular quenching rate constants $k_{\text {intra }}$ are independent of $D P$ and that the intermacromolecular quenching rate constants $k_{\text {inter }}$ decrease rapidly with $D P$. The effects of solvent on $k_{\text {intra }}$ and $k_{\text {inter }}$ are explained reasonably, based on the degree of expansion of polymer coils in solution.

\section{REFERENCES}

1. H. Ushiki, K. Horie, A. Okamoto, and I. Mita, Polym. J., 11, 691 (1979).

2. N. Goodman and H. Morawetz, J. Polym. Sci., C, 31, 177 (1970); ibid., A-2, 9, 1657 (1971).

3. M. Sisido, Macromolecules, 4, 737 (1971); Polym. J.,
4, 534 (1973); M. Sisido, Y. Imanishi, and T. Higashimura, Macromolecules, 9, 1657 (1976).

4. K. Shimada and M. Szwarc, J. Am. Chem. Soc., 97, 3313 (1975).

5. M. Yamamoto, K. Goshiki, T. Kanaya, and Y. Nishijima, Chem. Phys. Lett., 56, 333 (1978).

6. K. Horie, K. Tomomune, and I. Mita, Polym. J., 11, 539 (1979).

7. O. F. Olaj and K. H. Pelinka, Macromol. Chem., 177, 3413, 3427 (1976).

8. W. R. Krigbaum and P. J. Flory, J. Polym. Sci., 11, 37 (1953).

9. C. E. H. Bawn, C. Freemen and A. Kamaliddin, Trans. Faraday Soc., 46, 1107 (1950).

10. T. Homma, K. Kawahara, H. Fujita, and M. Ueda, Makromol. Chem., 67, 132 (1963). 